\title{
Análise da práxis docente em Biologia no ensino secundário português
}

\author{
Analysis of teaching praxis in Biology \\ in Portuguese High School
}

\begin{abstract}
Francisca Valkiria Gomes de Medeiros ${ }^{1}$. Ana Gláudia Vasconcelos Catunda ${ }^{2}$. Maria José Afonso Magalhães Rodrigues ${ }^{3}$. Cícero Antônio Maia Cavalcante ${ }^{2}$
\end{abstract}

\begin{abstract}
Resumo: A pesquisa objetivou analisar as práticas pedagógicas empregadas pelos professores portugueses de Biologia que favorecessem o desenvolvimento de habilidades e de competências no ensino desta disciplina. Participaram deste estudo 94\% dos professores de Biologia atuantes no Ensino Secundário da cidade portuguesa de Bragança (Nordeste de Portugal). A pesquisa caracteriza-se por seus aspectos qualitativos, descritivos e interpretativos. Para o levantamento dos dados, recorremos à entrevista semiestruturada; posteriormente os relatos foram transcritos e submetidos à análise de conteúdo. Os resultados revelaram que a infraestrutura existente nas escolas, a disponibilidade de bons equipamentos e de recursos são diferenciais no Ensino Secundário português. Entretanto, as dificuldades dos estudantes com o domínio da língua portuguesa, da matemática, entre outros, são grandes desafios a serem superados. Diante disso, conclui-se que uma práxis diversificada, que utilize estratégias como aulas laboratoriais e de campo, que utilize jogos educativos e aprendizagem cooperativa, pode melhorar a qualidade do ensino de Biologia.
\end{abstract}

Palavras-chave: Ensino de biologia. Prática docente. Ensino médio. Exame nacional de educação. Portugal.

\begin{abstract}
This research aimed to analyze the pedagogical practices used by the Portuguese biology teachers that might be able to improve the development of skills and competencies in the teaching of biology as a school subject. The study included $94 \%$ of the Biology teachers working in secondary education (High School) in the Portuguese city of Bragança. It is qualitative research, with a descriptive and interpretative nature. For the survey data, we used the semi-structured interview; then the data were transcribed and subjected to content analysis. The results showed that the infrastructure of schools and the availability of good equipment and resources vary in Bragança Secondary education, while there is a difficulty for the students with the knowledge of the Portuguese language, and Mathematics and other school subjects are major challenges to overcome. So, it is possible to claim that a diversified practice that uses strategies in laboratory and field classes, educational games and cooperative learning can improve the teaching of biology.
\end{abstract}

Keywords: Teaching of Biology. Teaching methods. National education exam. High school. Portugal.

\footnotetext{
${ }^{1}$ Universidade Estadual do Ceará (UECE), Limoeiro do Norte, CE, Brasil. E-mail: <valkiriagomes15@gmail.com>.

${ }^{2}$ Instituto Federal de Educação, Ciência e Tecnologia do Ceará (IFCE), Jaguaribe, CE, Brasil.

${ }^{3}$ Instituto Politécnico de Bragança (IPB), Escola Superior de Educação de Bragança (ESEB), Bragança, Portugal.
} 


\section{Introdução}

Face aos desafios da sociedade atual, a escola contemporânea tem assumido novas funções com vistas a preparar os alunos em todos os seus aspectos, seja o social, seja o pessoal, seja o profissional. Aprender a ler, a escrever e a decorar conceitos já não é considerado o suficiente nessa nova função, e os objetivos da educação tornaram-se cada vez mais amplos e diversificados.

Nesse novo contexto, o professor assume o papel de organizador/facilitador da ação pedagógica em detrimento da arcaica concepção de que ao magistério está destinada a tarefa única e exclusiva de transmitir aos alunos os saberes científicos tidos como absolutos, superiores, verdadeiros e, por isso, inquestionáveis (RODRIGUES; KRÜGER; SOARES, 2010). Sendo assim, o professor, através da sua práxis docente, tem como principal desafio direcionar os trabalhos pedagógicos buscando sempre incentivar a participação do aluno, promover o diálogo, a valorização dos interesses estudantis e a prática cidadã e social dos alunos. Nessa linha de raciocínio, Rodrigues, Moura e Testa (2011, p. 4) defendem que atualmente o professor "é um elemento incentivador, orientador e controlador da aprendizagem. Não é aquele que faz um ensinar passivo, mas um ensinar ativo, em que o aluno é sujeito da ação, e não sujeito-paciente".

As exigências sobre a atuação dos professores vêm-se modificando; o foco, antes baseado na memorização, passou a ser substituído pela capacidade de permitir a autonomia do indivíduo na produção e localização de conhecimentos. A escola passa a exigir novas características do docente, que deve ser capaz de estimular o aprendizado contínuo e o desenvolvimento de competências no estudante de modo que permitam a esse intervir na sociedade, buscando soluções para a resolução de situações-problema. Esse "novo" professor seria um organizador de situações de aprendizagem. (CAVALCANTE; LIMA, 2014, p. 30).

Frente a isso, as pesquisas educacionais no ensino fundamental e médio há algum tempo vêm demonstrando a necessidade de modificações nas tradicionais formas de ensino, que permanecem arraigadas na prática docente de muitos professores. (AMORIM, 2001). Esse fato aponta para a necessidade que os cursos de formação de professores têm de oferecer uma formação diferenciada da atual, e que, efetivamente, prepare o professor para a realidade social, econômica, tecnológica e científica da contemporaneidade e lhe dê condições de se reconstruir diante desse novo cenário.

Contudo, Saviani (2008) entende que essas modificações dos paradigmas da educação são legítimas, mas não alteram o caráter primeiro da educação formal, que é permitir ao aluno o acesso ao conhecimento científico e cultural, historicamente acumulado pela humanidade. Para o pesquisador, cada conteúdo, cada disciplina possuem finalidades políticas e sociais que se posicionam estrategicamente entre o aluno e o saber de que ele precisa se apropriar, para ter uma práxis social verdadeira e consciente. E é justamente aí que reside o grande desafio do professor.

Nessa perspectiva, a solidez do saber científico construído pelo estudante na sua vivência em sociedade e no seu período de instrução escolar é, sem dúvidas, a melhor e mais eficiente armadura contra as armadilhas causadas pela desinformação, despolitização e alienação, 
características de sociedades marcadas essencialmente pela desigualdade. Além disso, Oliveira e Wechsler (2002) defendem que os questionamentos sobre a eficiência no processo de ensino -aprendizagem e a busca por novas e criativas formas de ensino, que valorizem a prática social ativa do aluno, são questões que se apresentam aos professores.

No que se refere à prática social, em um mundo altamente modernizado é inquestionável que, atualmente, o ensino de Biologia exerce um papel estratégico no desenvolvimento da humanidade, pois possibilita, segundo Cachapuz et al. (2005, p. 17), “a formação de cidadãos susceptíveis de participar na tomada fundamentada de decisões em torno de problemas sociocientíficos e sociotecnológicos cada vez mais complexos".

A educação científica deve permitir que o cidadão analise situações cotidianas, compreenda problemas e desafios socioeconômicos e ambientais e tome decisões considerando conhecimentos técnico-científicos. Isso requer tanto o entendimento de explicações e teorias das várias disciplinas científicas, quanto o conhecimento sobre suas formas de produzir afirmações, de testar suas hipóteses e de usar evidências e justificativas; requer as relações entre a ciência, a tecnologia e a sociedade. (TRIVELATO; TONIDANDEL, 2015, p. 99).

Acerca deste assunto, Baptista (2015, p. 587) enfatiza que no ensino de ciências as "práticas pedagógicas devem ser comprometidas com a promoção do diálogo intercultural, ou seja, entre a cultura da ciência e as culturas dos estudantes". Essa postura no processo de ensino e aprendizado possibilita que os discentes reconheçam os conhecimentos que estudam como saberes que se manifestam em suas vidas cotidianas, mas que ao mesmo tempo têm gênese em aspectos históricos, sociais, culturais e tecnológicos intrínsecos da humanidade.

Todavia, Marandino, Selles e Ferreira (2009, p. 87) defendem que, atualmente, o ensino de Biologia no Ensino Médio/Ensino Secundário ainda privilegia:

[...] a descrição e a memorização; as aulas e avaliações dessas disciplinas escolares têm sido muitas vezes percebidas como pouco significativas para além do próprio universo acadêmico. Isso significa dizer que, em certos casos, temos valorizado conteúdos e métodos de ensino que devem ser aprendidos para que os estudantes apenas saibam os próprios conhecimentos biológicos, sem maiores conexões com finalidades de caráter mais pedagógico e/ou utilitário.

Geglio e Santos (2011, p. 78) acreditam que realmente "são abordados conteúdos importantes para a vida do cidadão como citologia, seres vivos, ecologia, genética, porém de maneira descontextualizada, sem que o aluno perceba a necessidade dessa aprendizagem para a sua vida comum”. Marandino, Selles e Ferreira (2009, p. 53) continuam sua análise, afirmando que "quando ensinamos Biologia no nível médio, ainda que reconheçamos a necessidade de tratar de conteúdos mais abstratos e vinculados ao mundo acadêmico, não deixamos de abordar outros conteúdos de caráter mais utilitário, isto é, que atendam às necessidades sociais de nossos alunos". 
Assim sendo, no campo do ensino da Biologia, é necessário o rompimento da distância entre as experiências de sucesso e os professores que precisam conhecê-las. Guimarães et al. (2015, p. 42) afirmam que "muitas experiências e bons procedimentos educacionais se mantêm presos na individualidade de cada professor. Com isso, uma ação, um processo didático ou uma inovação educacional perde a chance de ser útil e auxiliar toda a comunidade docente".

Foi nesse contexto que a possibilidade de realização de um intercâmbio de alunos brasileiros do curso Licenciatura em Ciências Biológicas do Instituto Federal do Ceará (IFCE), câmpus Jaguaribe, com o Instituto Politécnico de Bragança (IPB), localizado na cidade portuguesa de Bragança, permitiu aos pesquisadores vislumbrar a oportunidade de conhecer e analisar uma outra realidade educacional, para proporcionar uma reflexão sobre o ensino de Biologia em Portugal, que oportuniza e estimula reflexões pertinentes à realidade brasileira.

Diante disso, será apresentada uma breve explanação acerca da organização estrutural do Ensino Secundário e da disciplina de Biologia em Portugal. É importante ressaltar que o Ensino Secundário português corresponde ao Ensino Médio no Brasil. No entanto, esse sistema de ensino oferece quatro opções formativas diferentes para seus estudantes, que são os cursos: (1) Científico-humanísticos; (2) Planos próprios; (3) Artísticos especializados; e (4) Profissionais (PORTUGAL, 2016).

Os cursos Científico-Humanísticos são os mais procurados, já que constituem uma oferta educativa vocacionada para o prosseguimento dos estudos de nível superior (universitário ou politécnico). Esses são cursos que se destinam a alunos que tenham concluído o $9 .{ }^{\circ}$ ano de escolaridade ou equivalente. Têm a duração de três anos letivos, correspondentes aos $10 .^{\circ}, 11 .^{\circ}$ e 12. ${ }^{\circ}$ anos de escolaridade (PORTUGAL, 2016).

Esses cursos possuem como disciplinas obrigatórias para a formação geral dos alunos Português, Filosofia, Educação Física e uma opção de Língua Estrangeira, que pode ser Alemão, Espanhol, Francês ou Inglês. As demais disciplinas são específicas da área do conhecimento que o aluno escolher seguir, que pode ser: (1) Ciências e Tecnologias; (2) Ciências Socioeconômicas; (3) Línguas e Humanidades; (4) Artes visuais (PORTUGAL, 2016).

Apenas dentro do Curso de Ciências e Tecnologias é que os alunos estudam Matemática durante os três anos de duração do Ensino Secundário $\left(9^{\circ}, 10^{\circ}\right.$ e $11^{\circ}$ anos). As disciplinas Biologia e Geologia, Física e Química e Geometria Descritiva são estudadas no $10^{\circ}$ e no $11^{\circ}$ anos. No $12^{\circ}$ ano, os estudantes escolhem duas disciplinas para estudar, estando obrigatoriamente uma entre as opções Biologia, Física, Geologia e Química; a segunda poderá ser escolhida entre Antropologia, Aplicações Informáticas, Ciência Política, Clássicos da Literatura, Direito, Economia, Filosofia, Geografia, Grego, Língua Estrangeira e Psicologia (PORTUGAL, 2016).

Dessa forma, diferentemente do Brasil, no Ensino Secundário português, não existe a disciplina Biologia, única e exclusiva; a disciplina correspondente é Biologia e Geologia. No que se refere à abordagem dessas duas áreas do conhecimento pelos professores é importante destacar que:

De acordo com os Princípios Orientadores da Revisão Curricular do Ensino Secundário, a disciplina tem um programa nacional, devendo cada uma das suas áreas científicas, Biologia e Geologia, ser lecionada em cada um dos semestres a definir para cada ano letivo e com igual extensão, pretendendo-se alcançar uma situação de equilíbrio nas duas áreas científicas. 
Assim, sugere-se que no $10^{\circ}$ ano o $1^{\circ}$ semestre seja dedicado à Geologia e o $2^{\circ}$ semestre à Biologia, e no $11^{\circ}$ ano se alterne, isto é, inicie pela Biologia. No entanto, respeitando a autonomia das escolas, as suas especificidades e condições, poderão existir escolas onde se tenha de verificar o contrário, pelo que as duas áreas científicas se iniciam por um módulo inicial. (PORTUGAL, 2001, p. 3).

O Ministério da Educação de Portugal (PORTUGAL, 2001) aconselha que a carga horária das aulas de Biologia e Geologia sejam estimadas em quatro horas e meia, de modo que preferencialmente sejam ministradas em três aulas de noventa minutos durante a semana, "sendo uma delas exclusivamente de caráter prático, com a turma dividida em turnos". (PORTUGAL, 2001, p. 3).

Além disso, os Exames Nacionais do Ensino Secundário têm papel estratégico no direcionamento do trabalho docente realizado dentro das salas de aula do Ensino Secundário em Portugal, uma vez que atuam como um instrumento de avaliação externa da aprendizagem, desempenhando formalmente quatro funções primordiais: certificação, aferição, regulação e seleção (PORTUGAL, 2013, p. 7). A função de seleção desempenhada pelos exames dá-se pelo processo seletivo para o acesso ao Ensino Superior, que tem como base as notas dos estudantes nos cursos e a classificação dos referidos exames.

A função de certificação cumpre o papel de comprovar a realização de um dado conjunto de aprendizagens num determinado ciclo de ensino. A função de seleção encontra-se ligada à progressão escolar dos alunos e, em particular, no caso dos alunos do Ensino Secundário, ao acesso ao ensino superior. As funções de aferição e regulação permitem estabelecer algum meio de comparação e regulação entre escolas e um determinado controlo sobre o processo de ensino e de aprendizagem nas escolas. (PORTUGAL, 2013, p. 7-8).

Diante do exposto, os questionamentos iniciais que moveram esta pesquisa foram: (i) qual a realidade da práxis docente no Ensino de Biologia em Portugal?; (ii) quais os maiores desafios desse ensino?; (iii) como os Exames Nacionais do Ensino Secundário, que selecionam os alunos portugueses para a universidade, refletem-se na práxis docente e no aprendizado dos alunos? Portanto, acredita-se que as respostas a esses questionamentos possam colaborar para a melhoria da qualidade do ensino de Biologia.

Assim, esta pesquisa objetivou analisar a práxis docente de Biologia no Ensino Secundário de Bragança, Portugal, de acordo com a percepção dos próprios professores. Para que tal objetivo fosse alcançado foram propostos os seguintes objetivos específicos: (i) identificar o contexto em que o trabalho docente do professor de Biologia e Geologia se realiza em Bragança, Portugal; (ii) identificar as metodologias utilizadas por esses professores no processo de ensino-aprendizagem de Biologia; e (iii) compreender a influência dos Exames Nacionais do Ensino Secundário na prática pedagógica dos professores entrevistados. 


\section{Metodologia}

Esta pesquisa, de natureza qualitativa, possui caráter descritivo e interpretativo, pois apresenta, de forma integral, a opinião dos professores portugueses sobre o ensino de Biologia no seu país. Será interpretada à luz da legislação portuguesa.

A análise documental foi uma das técnicas adotadas durante a pesquisa, uma vez que documentos como leis, resoluções e programas curriculares foram utilizados com frequência, já que se apresentavam como ricas fontes de informações acerca da configuração que assume o sistema do Ensino Secundário em Portugal.

Além disso, duas abordagens se combinaram nesta pesquisa: uma de caráter analítico e outra de caráter compreensivo. A primeira permitiu quantificar características e percepções dos professores pesquisados; a segunda permitiu trabalhar de forma qualitativa as percepções dos professores acerca do ensino de Biologia nas escolas secundárias e a sua compreensão sobre o processo seletivo para ingresso nas universidades portuguesas.

O grupo amostral foi composto por dezesseis professores de Biologia, do Ensino Secundário, da cidade de Bragança, em um total possível de dezessete, totalizando aproximadamente $94 \%$ dos professores de Biologia da cidade. Bragança possui três escolas que oferecem o Ensino Secundário, o equivalente ao Ensino Médio no Brasil. Ressalta-se que todas as escolas que ofertam o Ensino Secundário em Bragança são públicas, sendo da responsabilidade do Ministério da Educação de Portugal. Nesse país, por força curricular no Ensino Secundário, as disciplinas de Biologia e de Geologia estão unidas, formando, assim, uma mesma disciplina. Porém, o escopo desta pesquisa objetiva apenas o ensino de Biologia.

Para recolha dos dados optou-se pelas entrevistas semiestruturadas gravadas em áudio, vídeo ou escritas, com o propósito de recolher informações sobre as opiniões, significados e acontecimentos ocorridos num determinado ambiente, como sugerem Rasco e Recio (2003).

Para Minayo (1994), a entrevista possibilita ao pesquisador a obtenção de informes contidos na fala dos atores sociais, enquanto o processo de filmagem permite reter vários aspectos do universo pesquisado.

No entanto, reiteramos a importância da elaboração de um guia de entrevistas, definindo o âmbito das questões (RASCO; RECIO, 2003), pois, como sugerem Bogdan e Biklen (1994, p. 135), "nas entrevistas semiestruturadas fica-se com a certeza de se obter dados comparáveis entre vários sujeitos". Contudo, a ordem e a sequência das questões apresentadas podem ser alteradas e, em muitas situações, explicitar e até mesmo reformular algumas delas para atender às necessidades. (MORGAN; GUEVARA, 2008).

No presente estudo, construímos o guia para a entrevista semiestruturada que foi fornecido previamente a cada um dos entrevistados e que foi construído obedecendo aos passos destacados por Cervo e Bervian (1983, p. 157-158):

1) $O$ entrevistador deve planejar a entrevista, delineando cuidadosamente o objetivo a ser alcançado.

2) Obter, sempre que possível, algum conhecimento prévio acerca do entrevistado.

3) Marcar com antecedência o local e o horário para a entrevista. Qualquer transtorno poderá comprometer os resultados da pesquisa. 
4) Criar condições, isto é, uma situação discreta para a entrevista, pois será mais fácil obter informações espontâneas e confidenciais de uma pessoa isolada do que de uma pessoa acompanhada ou em grupo.

5) Escolher o entrevistado de acordo com a sua familiaridade ou autoridade em relação ao assunto escolhido.

6) Fazer uma lista de questões, destacando as mais importantes.

7) Assegurar um número suficiente de entrevistados, o que dependerá da viabilidade da informação a ser obtida.

De posse do roteiro de entrevistas, foram marcados a data, a hora e o local para a coleta dos dados com o prévio consentimento e esclarecimento do grupo de professores colaboradores. Na condução da entrevista, foram considerados três momentos distintos: (i) justificativa do propósito da entrevista, ressaltando a importância da colaboração dos entrevistados para a investigação e garantindo o anonimato; (ii) desenvolvimento da entrevista de acordo com o guia prévio; e (iii) agradecimento aos participantes e reforço do pedido de disponibilidade para posteriores colaborações.

As entrevistas gravadas ou escritas foram realizadas no período de fevereiro a agosto de 2013, sendo posteriormente transcritas e submetidas à análise de conteúdo. Nessa etapa, todas as entrevistas foram digitadas de maneira fidedigna às falas dos professores. Dessa for$\mathrm{ma}$, as falas dos docentes foram organizadas em categorias que expressavam o pensamento e as contradições encontradas dentro do grupo entrevistado, a cada questionamento realizado. As expressões faciais e o tom de voz dos entrevistados também foram aspectos analisados, uma vez que naturalmente estão cheios de significados. Chizzotti (2006, p. 98) considera que o objetivo dessa técnica é "compreender criticamente o sentido das comunicações, seu conteúdo manifesto ou latente, as significações explícitas ou ocultas".

$\mathrm{Na}$ apresentação dos resultados optamos por apresentar textualmente algumas das falas dos docentes, uma vez que podem evidenciar com clareza as emergências que constituem as categorias criadas, neste momento os professores são identificados por letras maiúsculas, no sentido de se garantir a confidencialidade dos dados e o seu anonimato. A adição desses dois procedimentos possibilita melhor compreensão do contexto pesquisado aos leitores deste estudo. Os resultados obtidos serão apresentados e discutidos a seguir.

\section{Resultados e discussão}

O perfil socioeconômico da amostra indicou que os professores de Biologia de Bragança apresentavam faixa etária superior a 30 anos de idade. Especificamente, 31,25\% possuíam entre 30 e 40 anos; $18,75 \%$ tinham entre 40 e 50 anos; $43,75 \%$ tinham entre 50 e 60 anos; e $6,25 \%$ estavam na faixa entre 60 e 65 anos de idade.

Todos os professores entrevistados lecionavam há mais de dez anos, ou seja, são professores experientes. Além disso, $93,75 \%$ da amostra são professores efetivos; portanto, possuíam estabilidade em suas carreiras, conforme se percebe neste trecho de um dos depoimentos: " $A$ escola tem um corpo docente estável que todos os anos estão aqui. Os professores não estão aqui só um ano. Portanto, já conhecem toda a gente”. [Professor M]. 
Em relação à formação dos professores, verificou-se que todos possuíam diploma de licenciatura, sendo que 13\% também eram detentores do título de especialista e 37\% possuíam o título de mestre.

Os docentes relataram que as maiores dificuldades para o processo de ensino-aprendizagem da Biologia eram: a existência de muitos conteúdos programáticos, citada por cerca de $40 \%$ dos docentes entrevistados; a existência de turmas com elevado número de alunos, apontada como um desafio por aproximadamente 30\% dos professores; e 25\% dos entrevistados citaram as dificuldades dos alunos em relacionar os conteúdos pertencentes à Biologia e a áreas afins, além do frágil domínio da língua portuguesa por parte de alguns estudantes.

Os professores ainda revelaram a preocupação em lecionar todos os conteúdos previstos no currículo, perante a necessidade de os estudantes portugueses realizarem os Exames Nacionais como processo seletivo para entrada no Ensino Superior. Mencionaram que esse fato, muitas vezes, os impedem de recorrer a metodologias mais diversificadas e mais inovadoras, pois "têm de cumprir o programa" (Professor C). Portanto, torna-se perceptível a pesada influência que a avaliação externa exerce sobre o processo educacional dentro da escola, de forma a condicionar as práticas didático-pedagógicas dos professores, voltando a práxis docente para a obrigação da "transmissão" dos conteúdos científicos para os estudantes.

Em um sistema educativo, é no currículo que está expressa a função primordial da escola e é por esse motivo que se justifica a sua rígida normatização, uma vez que o ensino pautado na transmissão de conteúdos objetiva superar as cobranças impostas pelas avaliações externas, como é o caso dos Exames Nacionais, que, além de avaliarem o Ensino Secundário, selecionam os estudantes portugueses para o ingresso nas universidades. Conforme Arroyo (2013), essa perspectiva de educação é preocupante, pois obriga as escolas a prepararem alunos para atenderem às exigências do mercado econômico, transformando os professores em treinadores para provas específicas, e enfraquece a formação humanística dos jovens e a capacidade de refletirem sobre o mundo social.

Dessa forma, é necessário refletir acerca da influência que as avaliações exercem sobre a ação escolar, já que a verdadeira avaliação prepara o aluno para o objeto e para o que fazer com ele, permitindo autonomia, diferentemente da verificação, que apenas congela o objeto e as ações estudantis. (LUCKESI, 2002).

$\mathrm{Na}$ opinião dos professores entrevistados, a presença de mais de 20 alunos nas salas de aula pode ser considerada um problema, pois dificulta o processo de ensino-aprendizagem das disciplinas mediante a grande heterogeneidade de alunos que necessitam de atenção para o processo de construção do conhecimento. Pode-se analisar essa realidade no seguinte episódio:

\footnotetext{
Um grande desafio que temos não tem a ver especificamente com a Biologia, não tem a ver com a área científica, tem relação com o número de alunos, que acho que é demasiado. Acho que mais de 20 alunos em uma sala hoje se torna complicado. Hoje tenho mais on menos 27 alunos por sala, em média. Se for acima de 20, acho que prejudica o processo de ensino e aprendizagem. [Professor A].
}

Corroborando com esse relato, uma pesquisa realizada no ano de 2013 e divulgada em 2016 pela Organização para a Cooperação e Desenvolvimento Econômico (OCDE) constatou que muito tempo de aula nas escolas portuguesas é dedicado à tentativa de os professores manterem a ordem na sala. $\mathrm{O}$ estudo aponta que esse fato está relacionado com a quantidade 
de alunos presentes em cada sala de aula, que atualmente está estimada entre 26 e 30. (SOCIEDADE INDEPENDENTE DE COMUNICAÇÃO, 2016).

Sobre a dificuldade dos estudantes em relacionar os conteúdos, destacamos o seguinte depoimento de um dos entrevistados:

\begin{abstract}
Me preocupam principalmente as dificuldades que os alunos têm em interpretar as situações. Os alunos chegam ao secundário muito novos, e alguns têm dificuldade para perceber os conteúdos por falta de maturidade de raciocinio abstrato, e outros não conseguem compreender por serem a nível microscópico como reações químicas, e eles não têm o raciocino abstrato necessário para chegar a estas situações. Em outras situações, é mesmo a falta de dominio da lingua portuguesa, porque eles têm dificuldades de interpretar textos, documentos, gráficos. [Professor S].
\end{abstract}

Essa fala mereceu destaque, pelo fato de alguns professores terem mencionado as dificuldades que os estudantes enfrentam para a aprendizagem da Biologia decorrentes de problemas de interpretação de texto, análises matemáticas imprecisas, embasamentos químicos e à própria "interpretação" da Biologia na sua vida. Isso demonstra claramente que a Biologia não pode ser vista como uma disciplina isolada, sendo necessária uma abordagem inter e transdisciplinar. Ademais, o êxito no ensino-aprendizagem de qualquer disciplina só pode ser construído sobre as bases sólidas do ensino da língua materna e do raciocínio matemático. Parece que esse tem sido o grande desafio para os professores da atualidade. A elaboração de estratégias para a superação desse desafio apresenta-se como algo constante na vida docente.

No mundo todo, o magistério está submetido a vários condicionantes, entre eles, as políticas e diretrizes educacionais adotadas pelo país, as condições de trabalho do professor, a estabilidade e o prestígio da carreira, os salários, o contexto social e familiar dos alunos, as relações construídas dentro da escola e no seu entorno social. Sendo assim, a solidez ou a fragilidade do trabalho docente está associada ao estado de precarização ou não do trabalho do professor e do viver dos seus alunos. (ARROYO, 2013).

Os melhores índices educacionais estão nos países ricos, ou seja, onde há menos pobreza. Nesses países não é imposta à escola a obrigação de solucionar problemas sociais e econômicos que não foram criados pela escola e tampouco podem ser corrigidos por ela (CABRAL NETO; RODRIGUEZ, 2007). Dessa forma, não cabe à educação escolar o papel heroico de curar mazelas sociais. Pelo contrário, ela é capaz de bem cumprir seu papel quando lhe for oferecida a condição necessária para tal.

Nessa perspectiva, $56 \%$ dos entrevistados destacaram como o grande potencial que favorece o ensino de Biologia nas escolas de Bragança a adequada estrutura dos colégios e a disponibilidade de equipamentos. As escolas bragantinas possuem uma boa estrutura física, tecnológica, laboratorial e de bibliotecas. Além disso, 31\% da amostra apontou a presença de bons alunos como grande favorecimento para o sucesso do ensino da disciplina. Essa realidade pode ser exemplificada no relato abaixo apresentado:

Temos laboratórios novos, temos bons materiais de laboratório, temos bons equipamentos eletrônicos e informáticos, que simulam a parte que não podemos ver nos laboratórios. O contexto da escola é bom, a maioria dos alunos são todos da cidade e não têm muitos 
problemas econômicos, são apoiados pela escola. Temos projetores em todas as salas. Bem, estes são grandes potenciais de nossa realidade. [Professor M].

Quando os professores portugueses foram questionados sobre o que é preciso fazer para melhorar o processo de ensino-aprendizagem em Biologia, $75 \%$ responderam que é preciso mais tempo para que possam ser ministradas aulas práticas; $18,75 \%$ esperam que as provas dos Exames Nacionais se aproximem mais dos programas curriculares trabalhados pelas escolas portuguesas. Além do mais, a diminuição dos programas curriculares foi proposta por 18,75\% dos docentes; enquanto 12,5\% defendem mais tempo para as aulas teóricas de Biologia.

O elevado percentual de professores que desejavam mais tempo para as aulas práticas justifica-se pelo fato de essa ser uma das metodologias mais utilizadas pelos docentes de Biologia de Bragança, sendo adotada por 62,5\% dos entrevistados. As outras metodologias frequentemente adotadas são: a exposição oral dos conteúdos, utilizada por $50 \%$ dos professores, e o debate em sala, que também é adotado como metodologia frequente por 37,5\% dos educadores.

Apesar do exposto, Ferreira, Alencoão e Vasconcelos (2015) sugerem que, na realidade portuguesa, os alunos do Ensino Secundário não desenvolvem suficientes competências científicas. Segundo os mesmos autores, esse fato resulta "em parte, da existência de conteúdos curriculares e de metodologias pouco interessantes e insuficientemente apelativas para os jovens, não os seduzindo para o prosseguimento de estudos na área das ciências" (FERREIRA; ALENCOÃO; VASCONCELOS, 2015, p. 32).

No que se refere às aulas práticas, todos os professores afirmaram que elas exercem um papel fundamental para o ensino da Biologia, e que eles tentam relacioná-las com a teoria depois de uma explanação prévia, em que é feita a contextualização dos conteúdos com a vida cotidiana dos estudantes. Além disso, 25\% dos professores de Biologia lamentam, em suas falas, a retirada da disciplina de Técnicas Laboratoriais de Biologia, que outrora figurava no currículo das escolas secundárias portuguesas e se dedicava estritamente ao desenvolvimento de aulas práticas.

Em nível de Biologia, sinto muita falta da parte prática que nos tiraram, e esta área que é tão ligada à parte prática; foi um erro grave, em minha opinião. E agora somos obrigados a dar a prática e a teórica em um período muito curto, o que é impossivel. Então há esta dificuldade de se trabalhar a parte prática na área das ciências. [Professor E].

A este respeito, importa referir a Vygotsky (1984), que considera que o aspecto mais importante para o desenvolvimento intelectual humano é a convergência entre teoria e prática. Por sua vez, Krasilchik (2005) defende que as aulas práticas são fundamentais, pois permitem aos estudantes a aplicação prática do que estudam na teoria através de suas próprias indagações, iniciativas e experimentações. Portanto, as aulas práticas têm uma posição estratégica para o eficiente ensino da Biologia e das disciplinas científicas em geral.

Apesar de 50\% dos docentes terem afirmado que utilizam constantemente a exposição teórica dos conteúdos como estratégia didática frequente, todos foram unânimes em afirmar que não assumem uma postura tradicionalista, o que tornaria o ensino penoso e cansativo.

O professor $\mathrm{C}$ argumentou sobre o importante papel que desempenha o docente no processo de ensino-aprendizagem, relacionando essa importância com a necessidade de expor o conteúdo através da oratória. A reflexão desse professor está exposta a seguir:

Essa é uma questão complicada, o professor está a falar sobre a matéria que é encarada 
como uma visão tradicional do ensino, mas acho que é importante [...] O professor tem o conbecimento organizado, mas os alunos também têm algum, porém o professor pode levar a criar este conbecimento, a atingir este conhecimento através de um conjunto de ações, mas vai ser sempre necessário que o docente exponha. [Professor C].

Para Saviani (2008), os conteúdos precisam ser entendidos como prioridades, porque, sem conteúdos significantes, o ensino deixa de existir e a aprendizagem passa a ser uma farsa. E, sem essa aprendizagem, os grupos sociais desfavorecidos tornam-se fragilizados na luta por seus direitos e interesses. No entanto, cabe à escola procurar métodos de ensino eficazes, que despertem nos estudantes o prazer de estudar. Paralelamente a isso, fica reservada ao Estado a obrigação de oportunizar tais condições à escola. Sobre isso, Saviani (2008, p. 79) continua analisando:

Esses métodos devem estimular a iniciativa dos alunos sem abrir mão da iniciativa do professor. Favorecerá o diálogo entre alunos e docentes sem abrir mão do acesso à cultura e aos conhecimentos adquiridos historicamente. Valorizará os interesses dos alunos sem perder de vista a sistematização lógica do conhecimento.

Continuando com as análises dos resultados, o professor A afirma considerar que seus alunos estavam muito acostumados a serem meros espectadores das aulas (característica do tradicionalismo). Sobre essa temática, os docentes de Biologia de Bragança voltaram a citar as aulas práticas e as práticas laboratoriais como boas ferramentas para incentivar os estudantes a terem um posicionamento mais ativo/participativo no processo de ensino e aprendizado. Aulas de campo, aprendizagem-cooperativa e jogos educativos foram outras sugestões citadas pelos entrevistados.

Para mim, as aulas práticas são muito importantes [...] penso que elas ajudam a desenvolver algumas habilidades e competências como o raciocinio, verificação das hipóteses, formulações de questões, verificação dos materiais. As aulas práticas dão mais autonomia. [Professor J].

No entanto, durante as entrevistas foram obtidos registros que indicam a necessidade que os alunos sentem em "aprender" todo o conteúdo previsto nos currículos. Dessa forma, um ensino de Biologia mais voltado para a prática fica impossibilitado, pois "o maior problema é determinado pelo programa, que é muito extenso" (professor N) e "em consequência dos Exames que contam para a faculdade, os miúdos ainda acham que se souberem o livro, que se souberem de cor tudo decorado, vão tirar boa nota". (Professor A).

Um fato que contribui para tal situação é que a disciplina de Biologia e Geologia é uma das provas que têm mais pesos para o ingresso em cursos universitários muito concorridos, como, por exemplo, Medicina, Enfermagem e demais cursos ligados à área da saúde, da ciência e da tecnologia. A fala do professor S reflete essa situação:

Os estudantes, ao ingressarem no Ensino Secundário, optam por disciplinas especificas, que participam com maior peso na média de acesso dos Exames em relação às demais disciplinas que constituem a base comum; no caso dos alunos que estão a ter formação 
mais cientifica, uma delas é Biologia-Geologia, e outra é Físico-Quimica. Portanto, as médias que eles têm nessas disciplinas vão determinar, em larga escala, o que eles vão seguir na universidade. [Professor S].

Reflexões como esta evidenciam as indagações que os próprios professores portugueses fazem a respeito de como o currículo oficial e a seleção para as universidades se influenciam mutuamente e influenciam também o processo de ensino-aprendizagem da Biologia no dia a dia escolar, uma vez que o processo seletivo para o ingresso na universidade é um dos referenciais que orientam o trabalho docente e a aprendizagem discente nas escolas em todo o mundo.

Nessa perspectiva, o presente estudo revelou que 37,5\% dos professores entrevistados entendiam que a seleção para as universidades portuguesas deveria continuar seguindo a proposta atual, no qual as notas das provas dos estudantes ao longo do Ensino Secundário são somadas às notas dos Exames Nacionais e, a partir daí, os estudantes terão uma média para disputar uma vaga na universidade. Outros $12,5 \%$ consideravam que a seleção seria mais eficiente se realizada pelas próprias universidades; em igual percentual, 12,5\% defendem que os estudantes que optarem pela formação de caráter profissionalizante durante o Ensino Secundário deveriam ser mais valorizados. Além disso, $37,5 \%$ dos entrevistados apresentam opiniões diversificadas sobre o assunto.

Sobre o percentual de $37,5 \%$ dos professores que concordavam com esse processo seletivo, duas falas se destacaram. A primeira expressa a opinião do professor S, que concorda com o modelo de seleção vigente, pois acredita que esse sistema seletivo favorece os estudantes a se adaptarem à alta exigência que prontamente iriam encontrar na Educação Superior, como pode ser percebido no trecho da entrevista a seguir: "Se nós continuarmos a não exigir dos alunos do Ensino Secundário, maior será a dificuldade de adaptação ao Ensino Superior; os alunos percebem uma grande diferença ao chegarem lá”. [Professor S].

Essa maneira de pensar do professor S demonstra uma interpretação de que para os alunos "o objetivo último da educação é o desenvolvimento de comportamentos que serão vantajosos no futuro. Isso envolve ensinar comportamentos como autocontrole, resolução de problemas e tomada de decisão" (HENKLAIN; CARMO, 2013, p. 711-712). Ainda nessa perspectiva, o professor D acrescenta: "Considero importante que a avaliação de desempenho do aluno influencie no processo seletivo para vaga em um curso que ele mesmo escolbeu. É preciso que os alunos percebam que o seu trabalho vai ser merecedor de um determinado prêmio". [Professor D].

O professor A analisa sobre outro ponto de vista o atual sistema de seleção para a universidade portuguesa: "De fato, aqueles que querem mesmo ingressar na universidade, nestes três anos de Ensino Secundário são escravos. Eles se tornam precocemente responsáveis. Aqueles que querem, pois sabem que com média menor que 18 em uma escala que vai até 20 eles não entrarão em certos cursos". [Professor A].

Dentre os professores $(12,5 \%)$ que consideraram mais adequado as próprias universidades realizarem suas seleções, destaca-se a seguinte fala docente, que considera a mudança na forma de seleção justa para os alunos portugueses:

Não me parece adequado só um exame. Um exame é só um dia na vida do estudante em que ele faz a sua prova e define o seu futuro, e isso pode não corresponder ao desempenho do aluno durante o ano, ou seja, penso que as notas dos exames não deveriam ser quantificadas desta forma, de maneira tão alta. Outra opşão seríamos nós avaliarmos os estudantes durante o ano, e a universidade faria o seu próprio exame, o qual conste de conteúdos específicos, pois existem matérias que os alunos não utilizarão em determinados 
cursos. Por exemplo, em Medicina, não precisa de Geologia; por que está a fazer um exame que vale $50 \%$ da nota, Geologia? Não vai precisar tanto de Física, por que vai fazer um exame que pode influenciar tanto? Então acho que deveria ser mais especifico. [Professor C].

Em relação aos outros $12,5 \%$ dos professores que defenderam uma maior valorização dos estudantes que preferem seguir a corrente profissional e não necessariamente o ingresso na universidade, destaca-se a fala a seguir:

Reparem que hoje em dia toda gente vai para o Ensino Superior, de repente é preciso um carpinteiro e não bá, de repente é preciso um profissional que troca canos e coisas assim e não há. Portanto, o nosso ensino está revirado, pois passou toda a gente a ir pro curso superiorpara ser doutor, para ter a formação do Ensino Superior. [Professor E].

Além disso, entre os 37,5\% dos entrevistados que apresentaram opiniões diversas foram feitas suposições de que os Exames Nacionais não avaliavam de forma adequada os conhecimentos dos alunos: "O Exame não é adequado, deveria ser realizado um exame mais geral" (Professor $\mathrm{K})$; "Não existe uma relação adequada entre o ensino na escola e os exames nacionais" (Professor O); e ainda "Os alunos poderiam ser avaliados apenas pelos exames e não pelo desempenho no Ensino Secundário" (Professor L).

Dessa forma, para a maioria dos entrevistados (62,5\%), os Exames Nacionais do Ensino Secundário precisam ser reavaliados, uma vez que a função de avaliação do processo de ensino e aprendizado no Secundário e a função de seleção para a educação superior têm reflexos negativos na maneira como o currículo da Biologia é trabalhado, enrijecendo a prática pedagógica dos professores e inviabilizando a realização de aulas teórico-práticas.

\section{Considerações Finais}

Da análise realizada, destacamos que a adequada infraestrutura das escolas e o satisfatório provimento de equipamentos escolares, recursos tecnológicos, bons laboratórios e bibliotecas facilitam a prática docente portuguesa. É evidente que um bom processo de ensino-aprendizagem se realiza mais facilmente em ambientes que ofereçam condições para tal. Freire (2011, p. 27) dizia, sobre o dever do professor de exercer a sua missão como docente, que "para isso, precisa de condições favoráveis, higiênicas, espaciais, estéticas, sem as quais se move menos eficazmente no espaço pedagógico". Ainda conforme o referido autor, "às vezes, as condições são de tais maneiras perversas que nem se move. O desrespeito a este espaço é uma ofensa aos educandos, aos educadores e à prática pedagógica”.

Contudo, se a infraestrutura das escolas é um aspecto positivo identificado neste estudo, a sobrecarga de conteúdos no currículo do Ensino Secundário apresenta-se como uma fragilidade no sistema de ensino português, especificamente na opinião dos professores do Ensino Secundário de Bragança, pois a necessidade de preparar os alunos para os Exames Nacionais pressiona os professores a cumprirem rigorosamente este currículo, de modo que a práxis docente se torna limitada. Desse modo, os processos de seleção para o ingresso na Educação Superior portuguesa têm influenciado diretamente a prática docente, que acaba tendo que se 
adaptar para satisfazer a necessidade posterior de ingresso nas universidades, mesmo que isso resulte em prejuízos para os estudantes, uma vez que os exames realizados não conseguem mensurar de forma adequada as competências desenvolvidas pelos estudantes, evidenciando o desejo de mudança nos métodos utilizados para o ingresso nas universidades portuguesas da maioria dos professores.

Além disso, outros problemas se apresentam como desafios para o eficiente ensino -aprendizagem da Biologia, como, por exemplo, o domínio da língua portuguesa, dificuldades de interpretações matemáticas e dificuldades de entender as relações existentes no ramo da Biologia e de áreas afins. Esses fatores foram apontados como as principais dificuldades para o ensino da Biologia, o que demonstra que o entendimento da Biologia separado das outras disciplinas é impossível e que cabe ao professor utilizar abordagens cada vez mais transdisciplinares.

Para a superação desses desafios, as aulas laboratoriais e de campo, os jogos educativos e a aprendizagem-cooperativa são práticas pedagógicas que podem ser utilizadas pelos professores para diversificação de suas práticas e para o estímulo e desenvolvimento de competências junto aos estudantes, facilitando, assim, o ensino da Biologia.

Além do mais, esses tipos de práticas possibilitam aos estudantes a aproximação de vivências e experiências sociais, estimulando a análise e as indagações e, não menos importante, o trabalho em equipe. (ARROYO, 2013). É importante destacarmos que os conhecimentos científicos trabalhados na Biologia estão cheios de aplicações sociais e políticas; por isso, essa disciplina tem importante função para a sustentabilidade do mundo.

\section{Referências}

AMORIM, A. C. R. O que foge do olhar das reformas curriculares: nas aulas de biologia, o professor como escritor das relações entre ciência, tecnologia e sociedade. Ciência $\boldsymbol{\&}$ Educação, Bauru, v. 7, n. 1, p. 47-65, 2001. Disponível em: <http://dx.doi.org/10.1590/ S1516-73132001000100004>. Acesso em: 17 jul. 2014.

ARROYO, M. G. Currículo: território em disputa. Petrópolis: Vozes, 2013.

BAPTISTA, G. C. S. Um enfoque etnobiológico na formação do professor de ciências sensível à diversidade cultural: estudo de caso. Ciência $\boldsymbol{\&}$ Educação, Bauru, v. 21, n. 3, p. 585-603, 2015. Disponível em: <http://dx.doi.org/10.1590/1516-731320150030005>. Acesso em: 17 abr. 2017.

BOGDAN, R.; BIKLEN, S. Investigação qualitativa em educação: uma introdução à teoria e aos métodos. Porto: Porto Ed., 1994.

CABRAL NETO, A.; RODRIGUEZ, J. Reformas educacionais na América Latina: cenários, proposições e resultados. CABRAL NETO, A. et al. (Org.). Pontos e contrapontos da política educacional: uma leitura contextualizada de indicativos governamentais. Brasília: Líber, 2007. p. 5-45.

CACHAPUZ, A. et al. (Org.). A necessária renovação do ensino das ciências. São Paulo: Cortez, 2005. 
CAVALCANTE, C. A. M.; LIMA, I. B. Os conceitos de habilidades e competências do novo Enem: a percepção pedagógica dos professores de biologia. [Saarbrücken]: Novas Edições Acadêmicas, 2014.

CERVO, A. L.; BERVIAN, P. A. Metodologia científica: para uso dos estudantes universitários. 3. ed. São Paulo: McGraw-Hill, 1983.

CHIZZOTTI, A. Pesquisa em ciências humanas e sociais. 8. ed. São Paulo: Cortez, 2006.

FERREIRA, C.; ALENCOÃO, A.; VASCONCELOS, C. O recurso à modelação no ensino das ciências: um estudo com modelos geológicos. Ciência \& Educação, Bauru, v. 21, n. 1, p. 31-48, 2015. Disponível em: <http://dx.doi.org/10.1590/1516-731320150010003>. Acesso em: 17 abr. 2017.

FREIRE, P. Pedagogia da autonomia: saberes necessários à prática educativa. São Paulo: Paz e Terra, 2011.

GEGLIO, P. C.; SANTOS, R. C. As diferenças entre o ensino de biologia na educação regular e no EJA. Interfaces da Educação, Paranaíba, v. 2, n. 5, p. 76-92, 2011. Disponível em: <https://periodicosonline.uems.br/index.php/interfaces/article/view/594/558>. Acesso em: 17 abr. 2017.

GUIMARÃES, A. P. M. et al. Inovações no ensino de ciências e biologia: a contribuição de uma plataforma de colaboração online. In: SIMPÓSIO INTERNACIONAL DE EDUCAÇÃO E COMUNICAÇÃO, 6., 2015, Aracaju. Atas... Disponível em: < http:// proceedings.ciaiq.org/index.php/ciaiq2015/article/view/190/186>. Acesso em: 30 mar. 2015.

HENKLAIN, M. H. O.; CARMO, J. S. Contribuições da análise do comportamento à educação: um convite ao diálogo. Cadernos de Pesquisa, São Paulo, v. 43, n. 149, p. 704-723, 2013. Disponível em: <https://doi.org/10.1590/S0100-15742013000200016>. Acesso em: 7 jan. 2015.

KRASILCHIK, M. Prática de ensino de biologia. 4. ed. São Paulo: Edusp, 2005.

LUCKESI, C. C. Avaliação da aprendizagem escolar: estudos e proposições. São Paulo: Cortez, 2002.

MARANDINO, M.; SELLES, S. E.; FERREIRA, M. S. Ensino de biologia: histórias e práticas em diferentes espaços educativos. São Paulo: Cortez, 2009.

MINAYO, M. C. S.(Org.). Pesquisa social: teoria, método e criatividade. 3. ed. Petrópolis: Vozes, 1994.

MORGAN, D. L.; GUEVARA, H. Interview guide. In: GIVEN, L. M. (Ed.).The Sage encyclopedia of qualitative research methods. Los Angeles: Sage, 2008. p. 469-470.

OLIVEIRA, E. T. A.; WECHSLER, S. M. Variáveis que afetam a aprendizagem: percepção de alunos de licenciatura e professores. Psicologia Escolar e Educacional, Campinas, v. 6, n. 2, p. 133-139, 2002. Disponível em: <http://www.scielo.br/pdf/pee/v6n2/v6n2a03.pdf>. Acesso em: 3 jul. 2014. 
PORTUGAL. Direção-Geral da Educação. Biologia e geologia: documentos curriculares de referência. [2001]. Disponível em: <http://www.dge.mec.pt/biologia-e-geologia>. Acesso em: 2 abr. 2016.

PORTUGAL. Oferta formativa: ensino secundário. [2016]. Disponível em: < http://www. dge.mec.pt/oferta-formativa>. Acesso em: 2 abr. 2016.

. Processo de avaliação externa da aprendizagem: provas finais de ciclo / exames nacionais 2013. [Lisboa], 2013. Disponível em: < http://www.dge.mec.pt/sites/default/files/ JNE/2013_relatorioanual.pdf $>$. Acesso em: 1 abr. 2016.

RASCO, F. A.; RECIO, R. V. Los estudios de caso, una aproximación teorica. In: RECIO, R. V.; RASCO, F. A. (Coord.). Introducción a los estudios de casos: los primeros contactos com la investigación etnográfica. Málaga: Aljibe, 2003. p. 15-51.

RODRIGUES, L. P.; MOURA, L. S.; TESTA, E. O tradicional e o moderno quanto à didática do ensino superior. Revista Científica do ITPAC, Araguaína, v. 4, n. 3, p. 1-9, 2011. Disponível em: <http://www.itpac.br/arquivos/Revista/43/5.pdf>. Acesso em: 17 abr. 2017.

RODRIGUES, C.; KRÜGER, V.; SOARES, A. C. Uma hipótese curricular para a formação continuada de professores de ciências e de matemática. Ciência \& Educação, Bauru, v. 16, n. 2, p. 415-426, 2010. Disponível em: <http://dx.doi.org/10.1590/S1516$73132010000200010>$. Acesso em: 17 abr. 2017.

SAVIANI, D. Escola e democracia. Campinas: Autores Associados, 2008.

SOCIEDADE INDEPENDENTE DE COMUNICAÇÃO. Elevado número de alunos por turma dificulta ensino e aprendizagem. SIC Notícias, 5 abr. 2016. Disponível em: <http:/ / sicnoticias.sapo.pt/pais/2016-04-05-Elevado-numero-de-alunos-por-turma-dificulta-ensinoe-aprendizagem>. Acesso em: 1 maio 2016.

TRIVELATO, S. L. F; TONIDANDEL, S. M. R. Ensino por investigação: eixos organizadores para sequências de ensino de biologia. Ensaio: pesquisa em educação em ciências, Belo Horizonte, v. 17, n. spe, p. 97-114, nov. 2015. Disponível em: < http://dx.doi. org/10.1590/1983-2117201517s06>. Acesso em: 17 abr. 2017.

VYGOTSKY, L. S. A formação social na mente: o desenvolvimento dos processos psicológicos superiores. São Paulo: Martins Fontes, 1984.

Artigo recebido em 18/01/2016. Aceito em 25/09/2016.

Endereço para contato: Universidade Estadual do Ceará (UECE),

Faculdade de Filosofia Dom Aureliano Matos (FAFIDAM), Avenida

Dom Aureliano Matos, n. 2058, CEP 62930-000, Limoeiro do Norte,

CE, Brasil. 